\title{
of JURNAL REKONSTRUKSI DAN ESTETIK \\ Klebsiella Pneumoniae Necrotizing Fascitis of The Lower Extremity in A 7-Month-Old Male: A Case Report and Literature Review
}

Marelno Zakanito a, Iswinarno D. Saputro ${ }^{a^{*}}$

aDepartment of Plastic Reconstructive and Aesthetic Surgery, Faculty of Medicine Universitas Airlangga

*Corresponding author: Iswinarno D. Saputro - Department of Plastic Reconstructive and Aesthetic Surgery, Faculty of Medicine Universitas Airlangga. Email address : iswinarno@yahoo.com

ARTICLE INFO

Keywords:

Klebsiella pneumoniae

Necrotizing fasciitis

Lower extremity

\section{ABSTRACT}

Introduction: Klebsiella pneumoniae necrotizing fasciitis is an uncommon soft tissue infection characterized by rapidly progressing necrosis involving the skin, subcutaneous tissue, and fascia. This condition may result in gross morbidity and mortality if not treated in its early stages. In fact, the mortality rate of this condition is high, ranging from 25 to $35 \%$. We present a case of 7 -month-old male with K. pneumoniae necrotizing fasciitis of the lower extremity.

Materials and Methods: A 7-month-old male presented with large areas over both left and right inferior side of the lower limbs to the emergency department of Dr. Soetomo Academic Medical Center Hospital, Surabaya, Indonesia. Physical examination revealed elevated heart rate of 136 times per minute and increased body temperature of $38^{\circ} \mathrm{C}$. The large areas on both lower limbs were darkened, sloughed off, and very tender to palpation. A small area over the right hand was erythematous and sloughed off. Laboratory evaluation demonstrated decreased hemoglobin of $6.2 \mathrm{~g} / \mathrm{dL}$ and elevated leukocyte of 28,850 $\mathrm{g} / \mathrm{dL}$. Blood cultures demonstrated that K. pneumoniae was present.

Discussion: NF is usually hard to diagnose during the initial period. The findings of NF can overlap with other soft tissue infections including cellulitis, abscess or even compartment syndrome. However, pain out of proportion to the degree of skin involvement and signs of systemic shock should alert the clinical to the possibility of NF. The clinical manifestations of NF start around a week after the initiating event, with induration and edema, followed by 24 to 48 hours later by erythema or purple discoloration and increasing local fever In the next 48 to 72 hours, the skin turns smooth, bright, and serous, or hemorrhagic blisters develop. If unproperly treated, necrosis develops, and by the fifth or sixth day, the lesion turns black with a necrotic crust.

Conclusions: $K$. pneumoniae necrotizing fasciitis is a rare but lifethreatening disease. A high index of suspicion is required for early diagnosis and treatment of this condition 
$\mathrm{K}$

lebsiella pneumoniae necrotizing fasciitis (NF), characterized by rapidly , subcutaneous tissue, and fascia, is a severe and potentially life-threatening soft tissue infection. This condition is uncommon; however, it may result in gross morbidity and mortality if not treated in its early stages. Mortality associated with this condition is high, varying from 25 to $35 \%$. Among patients surviving NF, extensive scarring and physical and psychosocial impairmtn may result in isolation and profound psychological problems. NF most commonly affects lower extremities, accounting for approximately $50 \%$ of all cases. ${ }^{1,2}$ We present a case of 7 month-old male with $K$. pneumoniae necrotizing fasciitis of the lower extremity.

\section{Method}

A 7-month-old male presented with presented with large areas over both left and right inferior side of the lower limbs to the emergency department of Dr. Soetomo Academic Medical Center Hospital, Surabaya, Indonesia. Initially, five months prior to admission, he developed reddish lesions with bullae in the gluteus area, which went larger as the time went by. One week before admission, he developed fever accompanied by diarrhea with frequency of eight times per day.

Physical examination revealed elevated heart rate of 136 times per minute and increased body temperature of $38^{\circ} \mathrm{C}$. Large areas over both left and right inferior side of the lower limbs were darkened, sloughed off, and very tender to palpation (Fig 1). A small area over the right hand was erythematous and sloughed off (Fig 2).

Laboratory evaluation demonstrated decreased hemoglobin of $6.2 \mathrm{~g} / \mathrm{dL}$ and elevated leukocyte of $28,850 \mathrm{~g} / \mathrm{dL}$. Blood cultures demonstrated that $K$. pneumoniae was present. Based on clinical situation and laboratory examination results planned debridement and split thickness skin graft.
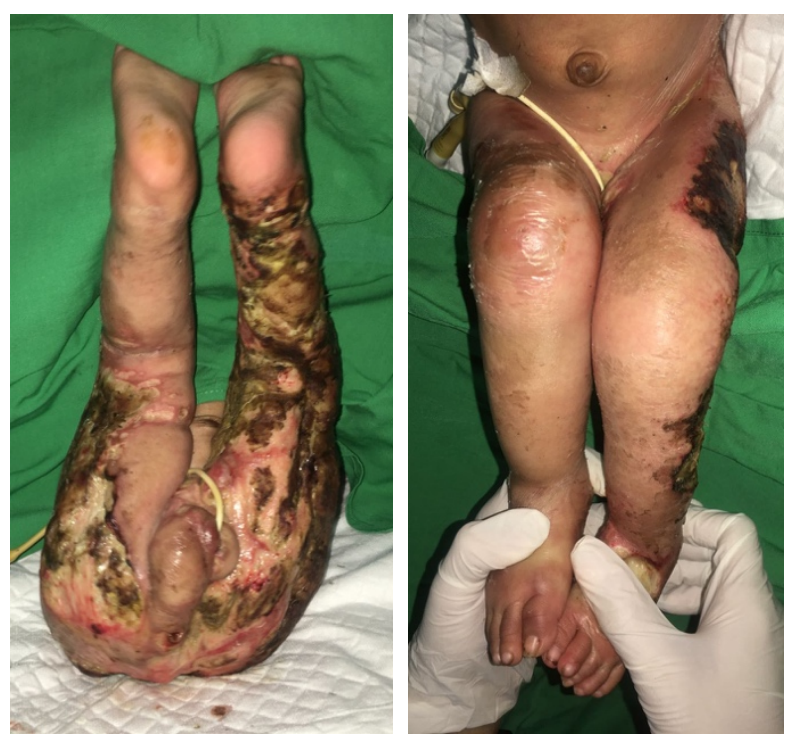

Fig 1. Inferior view of the lower limbs demonstrated large areas of the skin that were darkened, slough off, and very tender to palpation
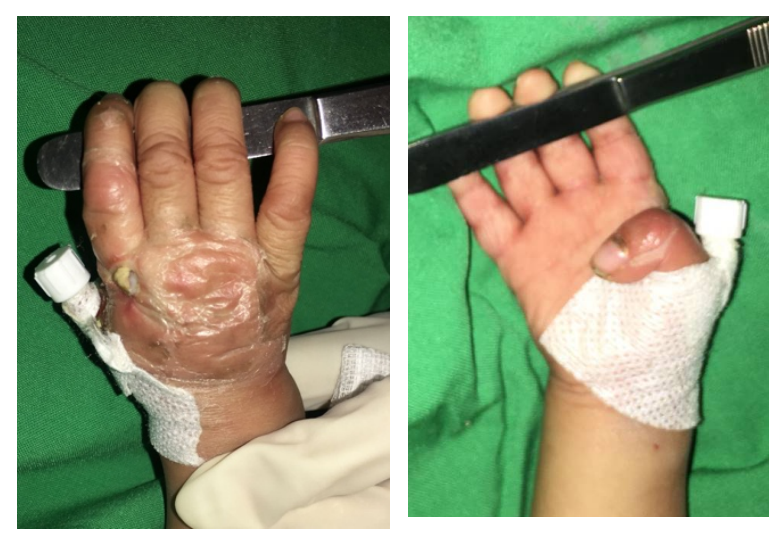

Fig 2. A small area over the right hand was erythematous and sloughed off 


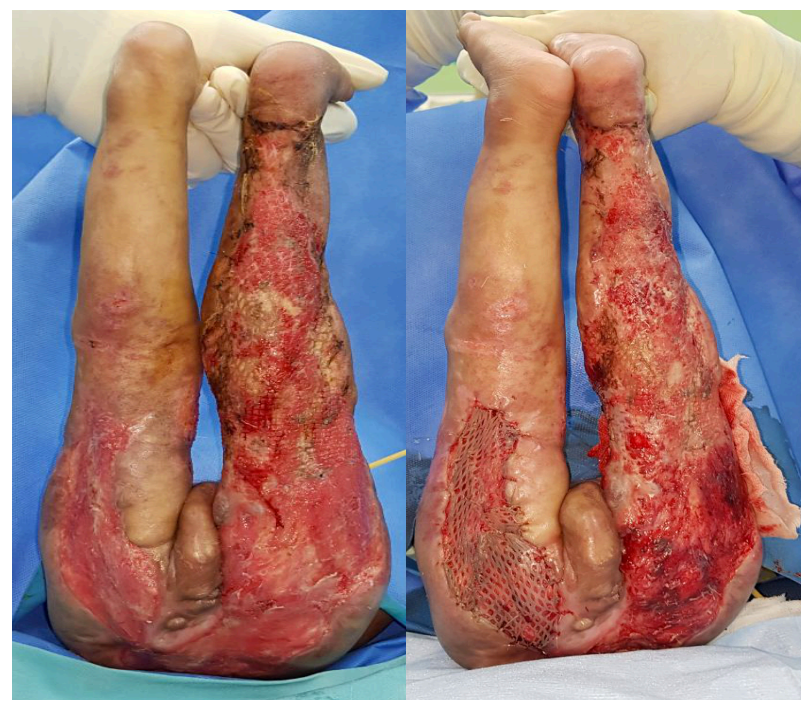

Fig 3. Inferior view of the lower limbs; left pict before skin graft inferior right femur, right pict after skin graft and debridement inferior both of femur.

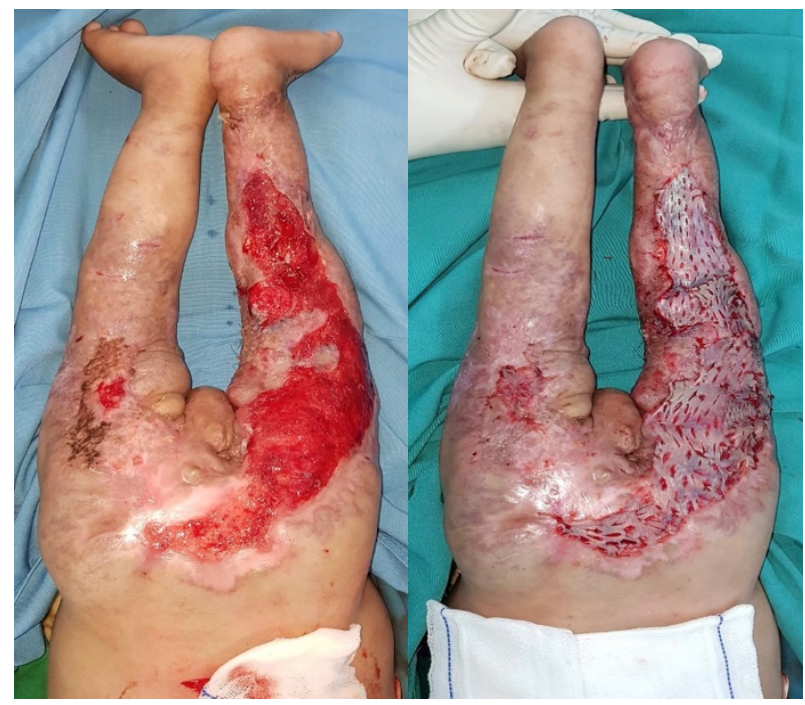

Fig 4. Inferior view of the lower limbs; right pict before skin graft inferior left femur, left pict after skin graft and debridement inferior both of femur.

\section{Discussion}

$\mathrm{NF}$ is rapidly spreading soft tissue involving the deep fascial layers, which cause secondary necrosis leading to significant mortality, which is around $25-35 \% \cdot{ }^{3-5}$ It is usually caused by the synergistic presence of various aerobic or anaerobic, gas producing or not, bacteria. Its progression is often fulminant, and it has been recognized for centuries. NF may appear in any anatomical region; multiple layers may be involved at times and, although the portal of entry is a rupture in the skin continuity, sometimes this cannot be found. ${ }^{6}$ One of the most sites that $\mathrm{NF}$ frequently affects is lower extremities, accounting for $50 \%$ of cases. The most important predictor of mortality is a delay in diagnosis; thereby it is crucial to make prompt diagnosis. ${ }^{4}$ Clinically, the findings of $\mathrm{NF}$ can overlap with other soft tissue infections including cellulitis, abscess or even compartment syndrome. However, pain out of proportion to the degree of skin involvement and signs of systemic shock should alert the clinical to the possibility of NF.7-9

$\mathrm{NF}$ is blood spread and quite often include postoperative infections, posttraumatic (i.e., perianal abscess). Despite careful monitoring, based on the initial pathological findings, the initial and aggressive treatment is the key to successful management, and often the final diagnosis of NSTI is confirmed in the operating theatre. Regardless of the clinical presentation, all patients need operative debridement, where repeated operations are often necessary. Therefore, the prognosis of NF depends on accurate and rapid diagnosis and early treatment. 6

$\mathrm{NF}$ is rare in children. ${ }^{10}$ It is reported that NF occurs in $0.03 \%$ of all hospitalization causes $^{11}$ and 0.08 per 100,000 children per year. ${ }^{12} \mathrm{NF}$ is more common in middle-aged adults, without sex, race, or geographic predilections. In adults, the lower extremities are more frequently affected, followed by the trunk and head. In children, most lesions most lesions are reported in the trunk. However, in a retrospective study of 39 children with NF, the lower extremities constituted the most common affected area, which occurred in 17 (44\%) subjects. ${ }^{10}$ 
In this case, we report a rare case of a 7month-old Indonesian male with NF caused by $K$. pneumoniae, which is a common causative pathogen in monomicrobial NF in Asia.13,14 Some cases also have been documented in Europe and the USA, mainly in patients who had traveled to Asia or were of Asian descent.15-19 The majority of cases described to date have been in Asians, raising the question of a genetic predisposition versus geographic strain acquisition. ${ }^{20}$

Although we did not perform skin biopsy, the leg wound was suspected to be the primary site of infection. A systematic study of monomicrobial $K$. pneumoniae NF showed that the initial infectious site was often on the lower extremities ${ }^{13}$; however, no preceding local factor was identified in half of the cases, and the infection showed a hematogenous spread, unlike the present case.13,17 The preceding local injury was probably the result of minor trauma; however, it is still an assumption. Initiating factors reported in previous studies include minor injuries ${ }^{21-25}$, surgical and traumatic wounds ${ }^{24,26}$, and varicella. ${ }^{27}$ In some cases, initiating factors cannot be identified.22,24,25

Usually, NF is hard to diagnose in the early period. This is due to the lack of cutaneous findings. Although a large necrotic area shows bacterial aggressiveness and fast spread, it is a delayed manifestation. ${ }^{6} \mathrm{NF}$ is manifested by severe pain localized at the trauma site. However, this is disproportionate to the physical findings, as skin usually doesn't carry any infection signs. When skin is involved, it is red-bluish due to vascular thrombosis. Fluctuation, tenderness, and exudates, not necessarily malodorous or purulent, might exist and skin is warm to palpitation. Lymph node involvement may also be seen, except in diffuse-type inflammations such as clostridium gangrene, .28 In more progressed cases, large hemorrhagic bullae, skin necrosis, sensory and motor deficits are commonly presented. ${ }^{6}$ In our case, the patient initially had reddish lesion with bullae.
Clinical manifestations of NF start around a week after the initiating event, with induration and edema, followed by 24 to 48 hours later by erythema or purple discoloration and increasing local fever. Pain is notable in the early stages, and sometimes crepitation exists. Tissue necrosis with nerve involvement causes hyposensitivity or anesthesia. In the next 48 to 72 hours, the skin turns smooth, bright, and serous, or hemorrhagic blisters develop. In unproperly treated, necrosis develops, and by the fifth or sixth day, the lesion turns black with a necrotic crust. Removal of the crust shows fascial tissues and a brown, grayish secretion. Subcutaneous cellular tissue is friable and easily removable. ${ }^{10}$

Systematic clinical symptoms, such as hypotension, fever (temperature $>38^{\circ} \mathrm{C}$ ), tachycardia, tachypnea, mental disturbance, tremor, and laboratory findings of marked increase in white blood cell count and metabolic acidosis are advanced indices of development of sepsis. ${ }^{6}$ Systemic signs and symptoms are the results of toxic process and septicemia. A high fever is disproportionate in relation to the size of the cutaneous lesion. Consciousness disturbance correlates with the severity of the process. Multiple organs and systems could be involved, and abscesses of the liver, lungs, spleen, brain, and pericardium may also develop. ${ }^{10}$

Necrotizing fasciitis is an infection of the fascia that can be caused by both grampositive bacteria, gram-negative and anaerobic bacteria in this case blood cultures demonstrated that $K$. pneumoniae was present. The symptoms are usually pain, erythema, bullae and necrosis, the diagnosis is mad by operative diagnosis in the form of a debridement biopsy. The principles management of Necrotizing Fascitis are operative (Debridement and Split Thickness Skin Graft), broad-spectrum antibiotics (Amikasin injection $2 \quad \mathrm{x} 50 \mathrm{mg}$ ) and oxygenation of infected tissue. 10 


\section{Conclusion}

K. pneumoniae necrotizing fasciitis is a rare but life-threatening disease. A high index of suspicion is required for early diagnosis and treatment of this condition.

\section{Bibliography}

1. 1. Tso DK, Singh AK. Necrotizing fasciitis of the lower extremity: imaging pearls and pitfalls. Br Inst Radiol. 2018.

2. Zhao J-C, Zhang B-R, Shi K, et al. Necrotizing soft tissue infection: Clinical characteristics and outcomes at a reconstructive center in Jilin Province. BMC Infect Dis. 2017;17(1). doi:10.1186/s12879-017-2907-6.

3. Chaudhry AA, Baker KS, Gould ES, Gupta R. Necrotizing fasciitis and its mimics: What radiologists need to know. Am J Roentgenol. 2015;204(1):128-139.

doi:10.2214/AJR.14.12676.

4. Fayad L, Carrino J, Fishman E. Musculoskeletal Infection: Role of CT in the Emergency Department. Radiographics. 2007;27(6):1723-1736. doi:10.1148/rg.276075033.

5. Hayeri MR, Ziai P, Shehata ML, Teytelboym OM, Huang BK. Soft-Tissue Infections and Their Imaging Mimics: From Cellulitis to Necrotizing Fasciitis. RadioGraphics. 2016;36(6):1888-1910. doi:10.1148/rg.2016160068.

6. Paramythiotis D, Koukoutsis H, Harlaftis N. Necrotizing soft tissue infections. Surg Pract. 2007;11(1):17-28. doi:10.1111/j.17441633.2007.00330.x.

7. Puvanendran R, Huey JCM, Pasupathy S. Necrotizing fasciitis. Can Fam Physician. 2009;55(10):981-987. doi:10.1016/j.amjopharm.2010.08.002.

8. Wong C-H, Wang Y-S. The diagnosis of necrotizing fasciitis. Curr Opin Infect Dis. 2005;18(2):101-106. doi:10.1097/01.qco.0000160896.74492.ea.

9. Goldstein EJC, Anaya DA, Dellinger EP. Necrotizing Soft-Tissue Infection: Diagnosis and Management. Clin Infect Dis. 2007;44(5):705-710. doi:10.1086/511638.

10. Fustes-Morales A, Gutierrez-Castrellon $P$, Duran-Mckinster C, Orozco-Covarrubias L, Tamayo-Sanchez L, Ruiz-Maldonado R. Necrotizing fasciitis: report of 39 pediatric cases. Arch Dermatol. 2002;138(7):893-899. doi:10.1001/archderm.138.7.893.

11. Fujisawa N, Yamada H, Kohda H, Tadano J, Hayashi S. Necrotizing fasciitis caused by Vibrio vulnificus differs from that caused by streptococcal infection. $J$ Infect. 1998;36(3):313-316. doi:10.1016/S01634453(98)94387-0.

12. Laupland KB, Davies HD, Low DE, Schwartz B, Green K, McGeer A. Invasive group A streptococcal disease in children and association with varicella-zoster virus infection. Ontario Group A Streptococcal Study Group. Pediatrics. 2000;105(5):E60E60. doi:10.1017/S0950268810001378.

13. Cheng NC, Yu YC, Tai HC, et al. Recent trend of necrotizing fasciitis in taiwan: Focus on monomicrobial Klebsiella pneumoniae necrotizing fasciitis. Clin Infect Dis. 2012;55(7):930-939. doi:10.1093/cid/cis565.

14. Ou LF, Yeh FL, Fang RH, Yu KW. Bacteriology of necrotizing fasciitis: a review of 58 cases. Chung Hua I Hsueh Tsa Chih. 1993;51(4):2715 ST-Bacteriology of necrotizing fasciitis: http://www.ncbi.nlm.nih.gov/htbinpost/Entrez/query? $\mathrm{db}=\mathrm{m} \&$ form $=6 \& \mathrm{dopt}=\mathrm{r} \&$ uid $=0008481845$.

15. Whallett EJ, Stevenson JH, Wilmshurst AD. Necrotising fasciitis of the extremity. J Plast Reconstr Aesthetic Surg. 2010;63(5). doi:10.1016/j.bjps.2009.09.011.

16. Kelesidis T, Tsiodras S. Postirradiation Klebsiella pneumoniae-associated necrotizing fasciitis in the Western hemisphere: A rare but life-threatening clinical entity. $A m \quad J$ Med Sci. 2009;338(3):217-224. doi:10.1097/MAJ.0b013e3181a393a4.

17. Decré D, Verdet C, Emirian A, et al. Emerging severe and fatal infections due to Klebsiella pneumoniae in two university hospitals in France. J Clin Microbiol. 2011;49(8):30123014. doi:10.1128/JCM.00676-11.

18. Gunnarsson GL, Brandt PB, Gad D, Struve C, Justesen US. Monomicrobial necrotizing fasciitis in a white male caused by hypermucoviscous Klebsiella pneumoniae. $J$ Med Microbiol. 2009;58(11):1519-1521. doi:10.1099/jmm.0.011064-0.

19. Persichino J, Tran R, Sutjita M, Kim D. Klebsiella pneumoniae necrotizing fasciitis in a Latin American male. J Med Microbiol. 2012;61(PART 11):1614-1616. doi:10.1099/jmm.0.043638-0. 
20. Shon AS, Bajwa RPS, Russo TA. Hypervirulent (hypermucoviscous) Klebsiella Pneumoniae: A new and dangerous breed. Virulence. 2013;4(2):107-118. doi:10.4161/viru.22718.

21. Giuliano A, Lewis F, Hadley K, Blaisdell FW. Bacteriology of necrotizing fasciitis. $\mathrm{Am} \mathrm{J}$ Surg. 1977;134(1):52-57. doi:10.1016/00029610(77)90283-5.

22. Meleney FL. Hemolytic streptococcus gangrene. Arch Surg. 1924;9(2):317-364. doi:10.1001/archsurg.1924.0112008008300 7.

23. WILSON B. Necrotizing fasciitis. Am Surg. 1952;18(4):416-431.

24. W.J. R. Necrotizing fasciitis. Ann Surg. 1970;172(6):957-964.

http://ovidsp.ovid.com/ovidweb.cgi?T=JS\&P AGE $=$ reference $\& D=$ emcl1 \&NEWS $=N \& A N=00$ 08833617.

25. Freeman HP, Oluwole SF, Ganepola G a, Dy E. Necrotizing fasciitis. $\mathrm{Am} J$ Surg. 1981;142(3):377-383.

26. Vijaykumar, Rao PS, Bhat N, Chattopadhyay A, Nagendhar MY. Necrotizing fasciitis with chickenpox. Indian J Pediatr. 2003;70:961963.

27. Brisse S, Fevre C, Passet V, et al. Virulent clones of Klebsiella pneumoniae: Identification and evolutionary scenario based on genomic and phenotypic characterization. PLoS One. 2009;4(3). doi:10.1371/journal.pone.0004982. 